\title{
Operative Techniques for Gliomas and the Value of Extent of Resection
}

\author{
Nader Sanai and Mitchel S. Berger \\ Department of Neurological Surgery, Brain Tumor Research Center, University of California at San Francisco, \\ San Francisco, California 94143
}

\begin{abstract}
Summary: Refinement of neurosurgical technique has enabled safer operations with more aggressive outcomes. One cornerstone of modern-day practice is the utilization of intraoperative stimulation mapping. In addition to identifying critical motor pathways, this technique can be adapted to reliably identify language pathways. Given the individual variability of cortical language localization, such awake language mapping is essential to minimize language deficits following tumor resection. Our experience suggests that cortical language mapping is a safe and efficient adjunct to optimize tumor resection while preserving essential language sites, even in the setting of negative mapping data. However, the value of maximizing glioma resections remains surprisingly unclear, as there is no general
\end{abstract}

consensus in the literature regarding the efficacy of extent of glioma resection in improving patient outcome. While the importance of resection in obtaining tissue diagnosis and alleviating symptoms is clear, a lack of Class I evidence prevents similar certainty in assessing the influence of extent of resection. Beyond an analysis of modern intraoperative mapping techniques, we examine every major clinical publication since 1990 on the role of extent of resection in glioma outcome. The mounting evidence suggests that, despite persistent limitations in the quality of available studies, a more extensive surgical resection is associated with longer life expectancy for both low-grade and high-grade gliomas. Key Words: Language mapping, motor tracts, cortical stimulation, extent of resection.

\section{INTRODUCTION}

CNS tumors are a major cause of morbidity and mortality with approximately 18,000 new cases of primary intracranial tumors diagnosed each year in the United States. This represents approximately $2 \%$ of all adult tumors in the country. More than half of these are highgrade gliomas. These lesions are extremely aggressive, and the vast majority of patients invariably have tumor recurrence, with the median survival time ranging from 1 to 3 years after initial diagnosis. Despite facing a better prognosis when compared with higher grade glial tumors, 50 to $75 \%$ of patients harboring low-grade gliomas eventually die of their disease. Median survival times have been reported to range between 5 and 10 years, and estimates of 10-year survival rates range from 5 to $50 \%$.

Although a primary tenet of neurosurgical oncology is that survival can improve with greater tumor resection, this principle must be tempered by the potential for func-

Address correspondence and reprint requests to: Mitchel S. Berger, M.D., Department of Neurological Surgery, USCF, 505 Parnassus Avenue, M779, Box 0112, San Francisco, CA 94143. E-mail: bergerm@ neurosurg.ucsf.edu. tional loss after a radical removal. Current neurosurgical innovations aim to improve our anatomic, physiologic, and functional understanding of the surgical region of interest to prevent potential neurological morbidity during resection. Emerging imaging technologies, as well as state-of-the-art intraoperative techniques, can facilitate extent of resection while minimizing the associated morbidity profile. Specifically, the value of mapping motor and language pathways is well-established for the safe resection of intrinsic tumors.

Interestingly, controversy persists regarding prognostic factors and treatment options for both low- and highgrade hemispheric gliomas. Among the various tumorand treatment-related measurements, including tumor volume, neurological status, timing of surgical intervention, and the use of adjuvant therapy, only age and tumor histology have been identified as reliable predictors of patient prognosis. Importantly, despite significant advances in operative technique and preoperative planning, the effect of glioma extent of resection in prolonging tumor-free progression and/or survival remains unknown. Although the importance of glioma resection in obtaining tissue diagnosis and decompressing mass ef- 
fect are unquestionable, a lack of class I evidence prevents similar certainty in assessing the influence of extent of resection. Even though low-grade and high-grade gliomas are distinct in their biologies, clinical behaviors, and outcomes, understanding the effect of surgery remains equally important for both.

\section{THE EVOLUTION OF CORTICAL MAPPING STRATEGIES}

Direct cortical stimulation has been used in neurosurgery since 1930 , first by Foerster, ${ }^{1}$ and then later, by Penfield et al..$^{2-4}$ In recent years, the technique of intraoperative cortical stimulation has been adopted for the identification and preservation of language function and motor pathways. Stimulation depolarizes a very focal area of cortex which, in turn, evokes certain responses. Although the mechanism of stimulation effects on language are poorly understood, the principle is based on the depolarization of local neurons and also of passing pathways, inducing local excitation or inhibition, as well as possible diffusion to more distant areas by way of orthodromic or antidromic propagation. ${ }^{5}$ Studies using optical imaging of bipolar cortical stimulation in monkey and human cortex have shown precise local changes (i.e., within 2 to $3 \mathrm{~mm}$ ) after the activation of cortical tissue. ${ }^{6,7}$ With the advent of the bipolar probe, avoidance of local diffusion and more precise mapping have been enabled with an accuracy estimated to be approximately $5 \mathrm{~mm}$.

Language mapping techniques were historically developed in the context of epilepsy surgery in which large craniotomies exposed the brain well beyond the region of surgical interest to localize multiple cortical regions containing stimulation-induced language and motor function (i.e., "positive" sites), prior to resection. Until recently, it has been believed that such positive site controls must be established during language mapping before any other cortical area could be safely resected. Using this tactic, awake craniotomies traditionally identify positive language sites in 95 to $100 \%$ of the operative exposures. However, brain tumor surgeons are now evolving toward a different standard of language mapping in which smaller, tailored craniotomies often expose no positive sites, and tumor resection is therefore directed by the localization of cortical regions that contained no stimulation-induced language or motor function (i.e., "negative" sites). This "negative mapping" strategy represents a paradigm shift in language mapping technique by eliminating the neurosurgeon's reliance on the positive site control in the operative exposure, thereby allowing for minimal cortical exposure overlying the tumor, less extensive intraoperative mapping, and a more time-efficient neurosurgical procedure.

\section{VARIABILITY IN CORTICAL LANGUAGE LOCALIZATION}

Prediction of cortical language sites through classic anatomical criteria is inadequate in light of the significant individual variability of cortical organization, ${ }^{8-11}$ the distortion of cerebral topography from tumor mass effect, and the possibility of functional reorganization through plasticity mechanisms. ${ }^{12-14}$ A consistent finding of language stimulation studies has been the identification of significant individual variability among patients. ${ }^{9}$ Speech arrest is variably located and can go well beyond the classic anatomical boundaries of Broca's area for motor speech. It typically involves an area contiguous with the face-motor cortex, and yet in some cases is seen several centimeters from the sylvian fissure. This variability has also been suggested by studies designed to preoperatively predict the location of speech arrest based on the type of frontal opercular anatomy ${ }^{15}$ or using functional neuroimaging. ${ }^{16-22}$ Similarly, for temporal lobe language sites, one study of temporal lobe resections assisted by subdural grids demonstrated that the distance from the temporal pole to the area of language function varied from 3 to $9 \mathrm{~cm} .{ }^{23}$ Functional imaging studies have also corroborated such variability. ${ }^{24}$ Furthermore, because functional tissue can be located within the tumor nidus, ${ }^{25}$ the standard surgical principle of debulking tumor from within to avoid neurologic deficits is not always safe. Consequently, the use of intraoperative cortical and subcortical stimulation to accurately detect functional regions and pathways is essential for safely removing dominant hemisphere gliomas to the greatest extent possible.

\section{AVOIDANCE OF FUNCTIONAL LANGUAGE DEFICITS AFTER AWAKE MAPPING}

Intraoperative cortical stimulation has yielded critical data regarding essential language sites, which seem to be organized in discrete mosaics that occupy a much smaller area of cortex than that described by traditional language maps. ${ }^{26-28}$ Interestingly, the majority of these language sites are surrounded by cortex that produce no language errors when stimulated. ${ }^{29}$ In the temporal lobe, identification of speech areas within the superior and middle temporal gyri have been documented within $3 \mathrm{~cm}$ of the temporal lobe tip. ${ }^{9}$ In this region, the distance of the resection margin from the nearest language site is the most important variable in predicting the improvement of preoperative language deficits. Accordingly, if the distance of the resection margin from the nearest language site is greater than 1 $\mathrm{cm}$, significantly fewer permanent language deficits occur. ${ }^{30}$ Strict adherence to this principle when oper- 
ating in any region of the dominant hemisphere can substantially reduce the risk of inadvertently resection functional tissue.

\section{PATIENT SELECTION AND THE ROLE OF FUNCTIONAL IMAGING FOR LANGUAGE LOCALIZATION}

Because the need to preserve cortical language function must be balanced with the goal of maximal tumor resection, intraoperative language mapping is advocated by some as the rule, rather than the exception. ${ }^{31}$ The greatest risk of tumor recurrence is located within $2 \mathrm{~cm}$ of the contrast enhancing rim on imaging studies, ${ }^{32,33}$ supporting the concept that the resection should ideally go beyond the gross tumor margin apparent on preoperative imaging. However, because of the infiltrating nature of gliomas, it is more than likely that a portion of the mass will occupy, or be continuous with, functional tissue. Again this emphasizes the need for cortical stimulation mapping to avoid injuring these critical areas, particularly language pathways. Although it is classically believed that patients who are neurologically intact or minimally affected preoperatively have their functional pathways either displaced or obliterated by infiltrative tumors, we now know that normally functioning language, motor, or sensory tissue can blend with the tumor. ${ }^{25}$ Therefore, it is not only patients with tumors located within the frontal operculum that benefit from intraoperative language mapping, but also those with lesions in proximity to this region, as there is significant variability in this region's anatomical and functional organization. $^{15,34}$

Functional imaging has experienced considerable advances in both technology and availability, raising the question of whether it may supplant intraoperative cortical stimulation mapping. Devices such as functional MRI, positron emission tomography, and magnetoencephalography may aid in the preoperative planning of the surgical resection strategy, but these techniques remain too imprecise for complex functions such as language mapping; their sensitivity (positron emission tomography, 75\%; functional MRI, 81\%) and specificity (positron emission tomography, 81\%; functional MRI, $53 \%$ ) are suboptimal. ${ }^{24,35}$ These modalities highlight language-associated areas of indeterminate significance, ${ }^{36}$ and they do not offer real-time intraoperative information. Consequently, for the identification of functional language pathways and guidance of safe tumor removal, these diagnostic imaging tools are still only supplements, not substitutes, for direct intraoperative stimulation mapping.

\section{SPECIALIZED NEUROANESTHESIA FOR THE AWAKE CRANIOTOMY}

An experienced neuroanesthesia team is of paramount importance in not only achieving an accurate intraoperative language map, but in assuring a short and uncomplicated postoperative recovery. As compared to asleep craniotomies, awake craniotomies are associated with less procedural morbidity and fewer postoperative complications, ${ }^{31}$ which is a testimony to the safety of the neuroanesthetic regimen for awake mapping.

In our practice, patients are premedicated with midazolam and monitoring, including a blood pressure cuff and an axillary temperature probe, which is applied prior to positioning. Sedation is achieved with propofol (up to $100 \mu \mathrm{g} / \mathrm{kg} / \mathrm{min})$ and remifentanil $(0.05 \mu \mathrm{g} / \mathrm{kg} / \mathrm{min}$ and higher). Propofol/remifentanil boluses are also used for Foley insertion and Mayfield head holder pin application. As an additional measure, the neurosurgeon provides scalp analgesia with generous injection of lidocaine/marcaine. Once the bone flap is removed, all sedatives are discontinued and the patient is asked to hyperventilate prior to dural opening. The dura is then infiltrated with lidocaine around the middle meningeal artery to avoid the discomfort associated with dural opening. No sedatives are administered during mapping and intravenous methohexital $(10 \mathrm{mg} / \mathrm{mL})$, as well as topical ice cold Ringer's solution were available for seizure suppression. ${ }^{37}$ Once mapping is complete, sedation is achieved with dexmedetomidine (up to $1 \mu \mathrm{g} / \mathrm{kg} / \mathrm{min}$ ) and remifentanil $(0.05 \mu \mathrm{g} / \mathrm{kg} / \mathrm{min}$ and higher).

\section{CURRENT INTRAOPERATIVE LANGUAGE MAPPING TECHNIQUES}

In general, a limited craniotomy should expose the tumor and up to $2 \mathrm{~cm}$ of surrounding brain. Using bipolar electrodes, cortical mapping is started at a low stimulus $(1.5 \mathrm{~mA})$ and increased to a maximum of $6 \mathrm{~mA}$, if necessary. A constant-current generator delivers biphasic square wave pulses (each phase, $1.25 \mathrm{~ms}$ ) in 4-second trains at $60 \mathrm{~Hz}$ across 1-mm bipolar electrodes separated by $5 \mathrm{~mm}$. Stimulation sites (approximately 10 to 20 per subject) can be marked with sterile numbered tickets. Throughout language mapping, continuous electrocorticography should be used to monitor afterdischarge potentials, and therefore eliminate the chance that speech or naming errors are caused by subclinical seizure activity. Some groups advocate the use of language mapping along subcortical white matter pathways, as well. ${ }^{38,39}$

Speech arrest is based on blocking number counting without simultaneous motor response in the mouth or pharynx. Dysarthria can be distinguished from speech arrest by the absence of perceived or visible involuntary muscle contraction affecting speech. For naming or read- 
ing sites, cortical stimulation is applied for 3 seconds at sequential cortical sites during a slide presentation of line drawings or words, respectively. All tested language sites should be repeatedly stimulated at least three times. A positive essential site can be defined as an inability to name objects or read words in $66 \%$ or greater of the testing per site. In all cases, a $1-\mathrm{cm}$ margin of tissue should be measured and preserved around each positive language site to protect functional tissue from the resection. ${ }^{40}$ The extent of resection is directed by targeting contrast-enhancing regions for high-grade lesions and T2-hyperintense areas for low-grade lesions.

\section{FUNCTIONAL OUTCOME AFTER LANGUAGE MAPPING FOR DOMINANT HEMISPHERE GLIOMAS}

Despite the considerable evidence supporting the use of intraoperative cortical stimulation mapping of language function, the efficacy of this technique in preserving functional outcome after aggressive glioma resection remains poorly understood. Nevertheless, the long-term neurological effects after using this technique for large, dominant-hemisphere gliomas are important to define to accurately advocate its use. ${ }^{41}$

Our experience with 250 consecutive dominant hemisphere glioma patients (World Health Organization grades II-IV) suggests that functional language outcome after awake mapping can be favorable, even in the setting of an aggressive resection. ${ }^{42}$ Overall, 159 of these 250 patients $(63.6 \%)$ had intact speech preoperatively. At 1 week postoperatively, 194 patients $(77.6 \%)$ remained at their baseline language function, whereas 21 (8.4\%) worsened and $35(14.0 \%)$ had new speech deficits. However, by 6 months, $52(92.8 \%)$ of 56 patients with new or worsened language deficits returned to baseline or better, and the remaining $4(7.1 \%)$ were left with a permanent deficit. Interestingly, among these patients, any additional language deficit incurred as a result of the surgery improved by 3 months or not all (FIG. 1). Thus, using language mapping, only $1.6 \%$ (4 of 243 surviving patients) of all glioma patients had a permanent postoperative language deficit develop. One explanation for this favorable postoperative language profile may be our strict adherence to the "1-centimeter rule," first described by Haglund et al., ${ }^{30}$ which demonstrated that a resection margin of $1 \mathrm{~cm}$ or more from a language site for temporal lobe tumors significantly reduces postoperative language deficits.

\section{TAILORED CRANIOTOMIES AND THE VALUE OF NEGATIVE LANGUAGE MAPPING}

In contrast to the classic mapping principles practiced in epilepsy surgery in which 95 to $100 \%$ of operative

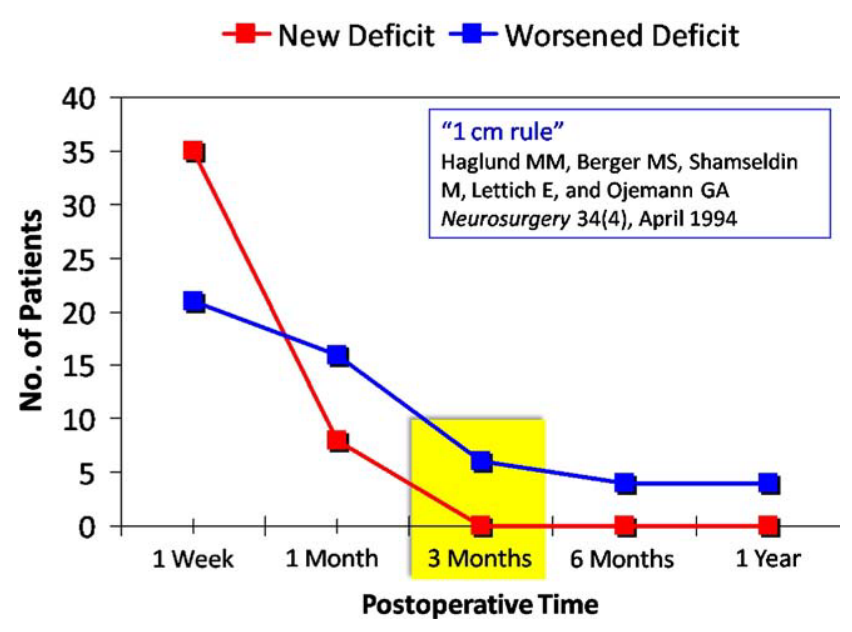

FIG. 1. Temporal profile of language deficit resolution after resection of dominant hemisphere gliomas.

fields contain a positive language site, a paradigm shift is emerging in brain tumor language mapping, in which positive language sites are not always found prior to resection (FIG. 2). In our practice, because of our use of tailored cortical exposures, less than $58 \%$ of patients have essential language sites localized within the operative field. Our experience suggests that it is safe to use a minimal exposure of the tumor and resect based on a negative language map, rather than rely on a wide craniotomy to find positive language sites well beyond the lesion. However, language mapping techniques such as this are generally more successful and safer at highvolume neurosurgical centers.

Negative language mapping, however, does not necessarily guarantee the absence of eloquent sites. Despite negative brain mapping, permanent postoperative neurologic deficits have been reported. ${ }^{31}$ In our experience with 250 consecutive dominant hemisphere glioma patients, all 4 of our patients with permanent postoperative neurologic deficits had no positive sites detected prior to their resections. Other cases of unexpected postoperative deficits have also been attributed to progressive tumor infiltration into functional areas. ${ }^{43}$ Furthermore, both intraoperative stimulation and functional imaging techniques have provided evidence for redistribution of functional neural networks in cases of stroke, ${ }^{13,44,45}$ congenital malformations, ${ }^{46,47}$ brain injury, ${ }^{48}$ and tumor progression. ${ }^{13,14,49}$ Not surprisingly, it has been hypothesized that brain infiltration by gliomas leads to reshaping or local reorganization of functional networks as well as neosynaptogenesis. ${ }^{50,51}$ This would explain the frequent lack of clinical deficit despite glioma growth into eloquent brain areas, ${ }^{13,49,52}$ as well as the transient nature of many postoperative deficits. In the case of language function located in the dominant insula, the brain's capacity for compensation of functional loss has also been associated 


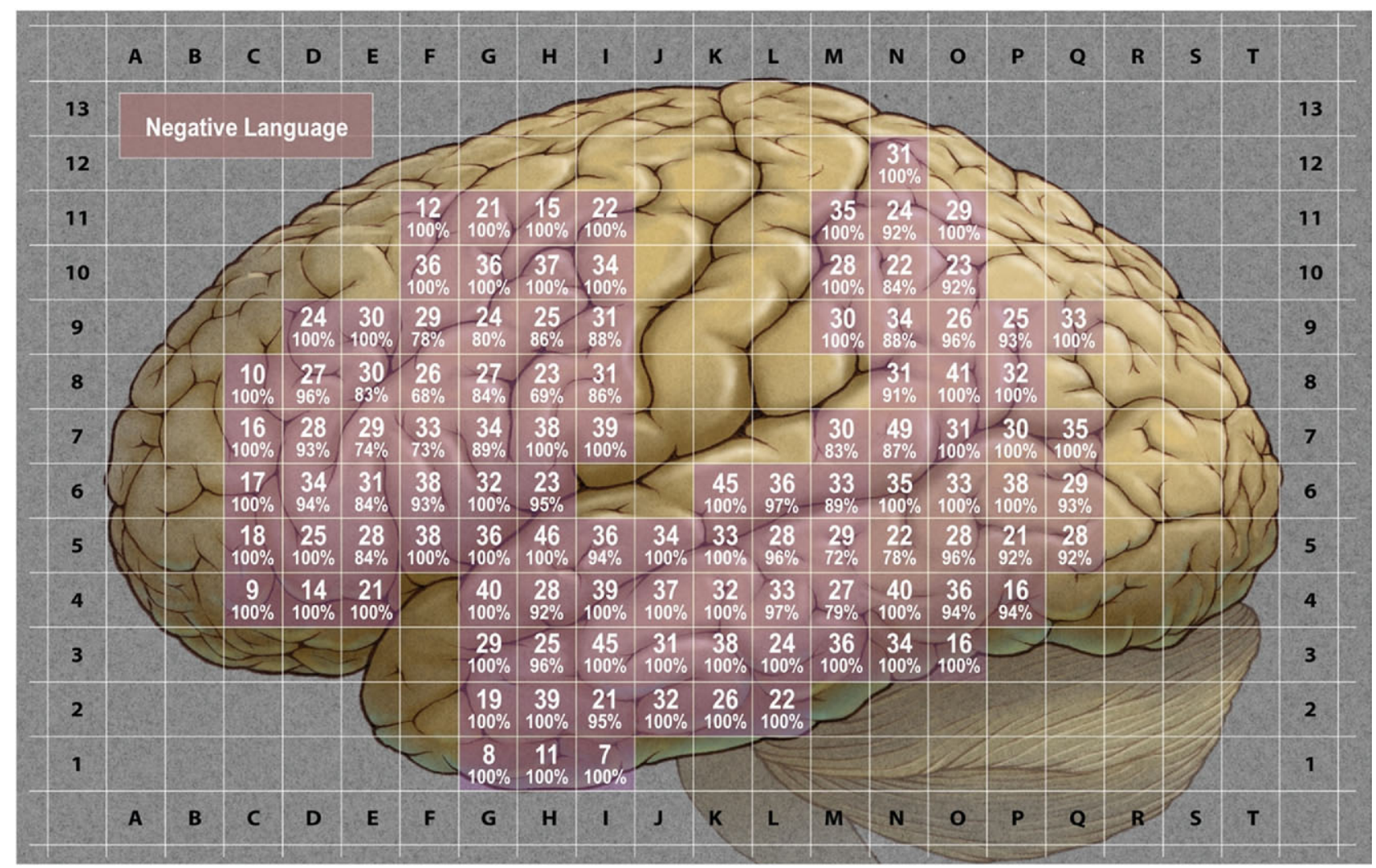

FIG. 2. Negative language map indicating the percentage of negative stimulations per square centimeter of the dominant cerebral hemisphere.

with recruitment of the left superior temporal gyrus and left putamen. ${ }^{52}$

\section{AN EVIDENCE-BASED APPROACH TO UNDERSTANDING THE VALUE OF EXTENT OF RESECTION}

Microsurgical resection remains a critical therapeutic modality for all gliomas. ${ }^{53-56}$ However, there remains no general consensus in the literature regarding the efficacy of extent of resection in improving patient outcome. ${ }^{57-63}$ With the exception of World Health Organization grade I tumors, gliomas are difficult to cure with surgery alone, and the majority of patients will experience some form of tumor recurrence. Patients with glioblastomas have median survival rates of 12.2 to 18.2 months, ${ }^{64}$ whereas those with anaplastic astrocytomas can expect to survive 41 months, on average. ${ }^{65}$ Low-grade gliomas carry a better prognosis, although the vast majority of patients eventually die of their disease and 5-year survival percentages range from 42 to $92 \%$ in the literature. ${ }^{66-73}$

For all gliomas, the identification of universally-applicable prognostic factors and treatment options remains a great challenge. Among the many tumor- and treatmentrelated measurements, only patient age and tumor histology have been identified as reliable predictors of patient prognosis, although functional status can also be statis- tically significant. Surprisingly, despite significant advances in brain tumor imaging and intraoperative technology during the last 15 years, the effect of glioma resection in extending tumor-free progression and patient survival remains unknown.

Although low-grade and high-grade gliomas are distinct in their biology, clinical behavior, and outcome, understanding the efficacy of surgery remains equally important for each. With this in mind, an examination of the modern neurosurgical literature (1990 to present) reveals clues as to the role of extent of resection in glioma patient outcome (FIG. 3).

\section{Low-grade glioma extent of resection studies}

Twenty studies ${ }^{66-71,74-87}$ since 1990 have applied statistical analysis to examine the efficacy of extent of resection in improving survival and delaying tumor progression among low-grade glioma patients. Five of these studies included volumetric analysis of extent of resection. ${ }^{78,79,83,86,88}$ Of the nonvolumetric studies, $12 \mathrm{dem}$ onstrated evidence supporting extent of resection as a statistically significant predictor of either 5-year survival or 5-year progression-free survival. These studies were published from 1990 to 2005, and a combination of multivariate and univariate analyses to determine statistical significance was most commonly used. In most instances, extent of resection was defined on the basis of 


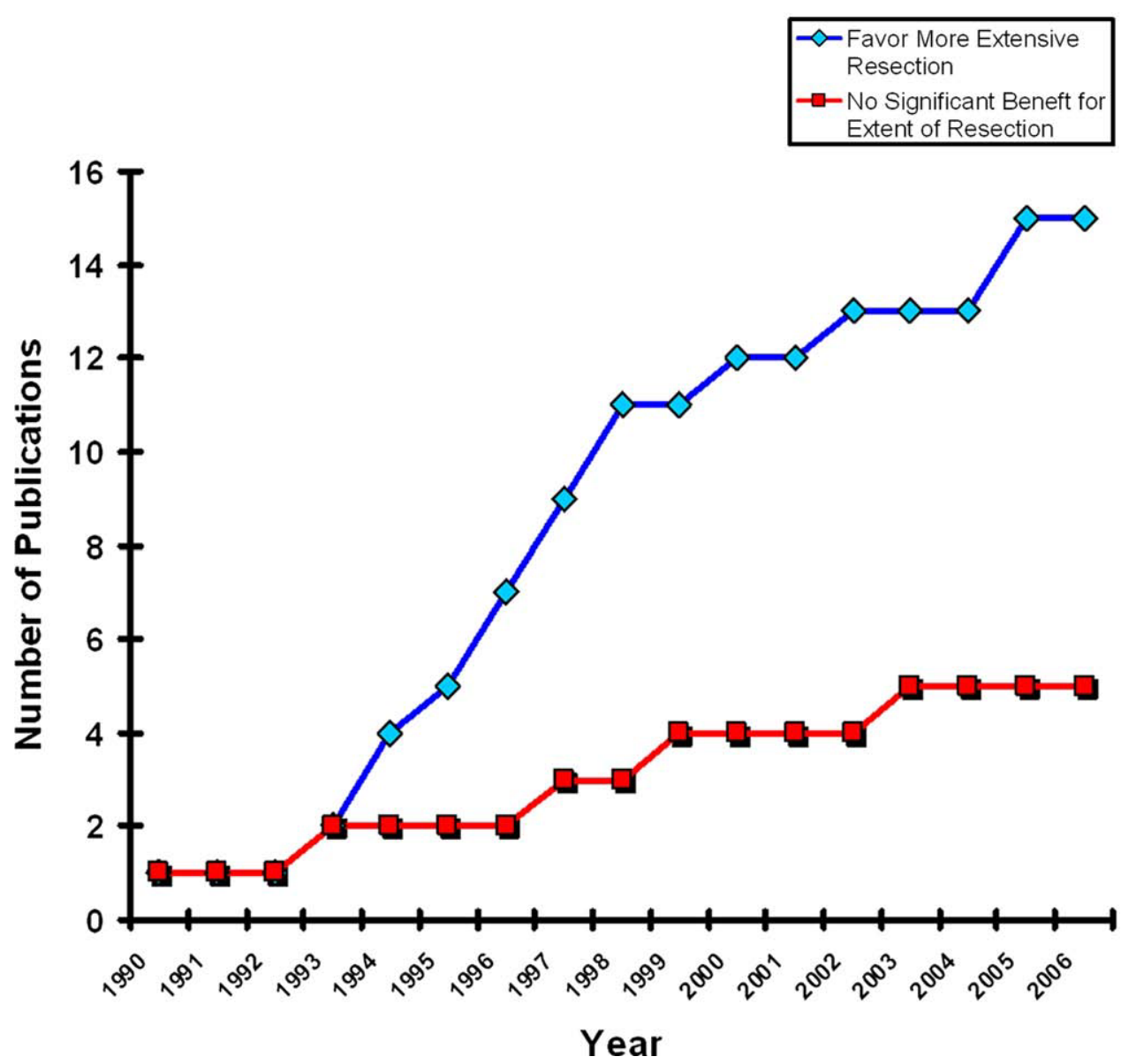

FIG. 3. Trends in the relative numbers of studies in the neurosurgical literature since 1990 statistically examining the impact of extent of resection on patient survival.

gross-total versus subtotal resection. Interestingly, only three nonvolumetric studies did not support extent of resection as a predictor of patient outcome. However, none of these reports evaluated progression-free survival, but instead focused solely on 5-year survival. Of the five volumetric low-grade glioma studies reviewed, four demonstrated statistical significance based on 5-year survival. For their statistical analyses, each study divided the extent of resection percentages into two categories, although the cutoff threshold was different in each publication and varied from 75 to $100 \%$.

\section{High-grade glioma extent of resection studies}

Thirty studies ${ }^{40,56,65,89-114}$ since 1990 have applied statistical analysis to examine the efficacy of the extent of resection in improving survival and delaying tumor progression among high-grade glioma patients. Four of these studies included volumetric analysis of extent of resection. ${ }^{40,56,65,108}$ Of the nonvolumetric studies, 16 demonstrated evidence supporting extent of resection as a statistically significant predictor of either time to tumor progression or overall survival. Although some of these reports showed extent of resection to significantly affect both tumor progression and overall survival, every study showed a survival benefit. Ten studies, however, demonstrated no significant benefit based on extent of resection. Notably, the distribution of adjuvant chemotherapy and radiation treatment was comparable among all highgrade glioma extent of resection studies. Echoing the nonvolumetric study results, half of all high-grade volumetric studies showed a significant survival advantage with greater extent of resection.

Although the high-grade studies reviewed were all modern series conducted by expert neurosurgeons with access to comparable operative technologies, it remains difficult to define the many inherent disparities between the cases described that may have biased the reported findings. One factor that may distinguish various highgrade glioma studies from one another is the distribution of World Health Organization grades III and IV histologies among the study patients. After quantifying this measurement in each publication, it remains difficult to draw any firm conclusions regarding causality. Another dimension of extent of resection analysis that can greatly affect the reported findings is the method with which the extent of resection is calculated. Although volumetric MRI analysis is now the gold standard, many centers still 
rely upon the surgeon's report or two-dimensional analysis based on postoperative MRI. However, in examining the distribution of extent of resection methodologies and comparing them to the findings for both low-grade and high-grade gliomas, there appears to be a relatively even distribution of techniques for each study category.

\section{Quantification of improvement in patient outcome}

For both low- and high-grade gliomas, one can define the mean survival time associated with subtotal versus gross-total resection in the modern neurosurgical literature. Although the level of evidence available for each tumor category does not permit a statistical meta-analysis, this measurement provides an overall estimation of the additional survival time these studies suggest may be gained through a greater extent of resection. Not surprisingly, the effect of a greater extent of resection was more pronounced in the low-grade glioma studies in which the mean survival was extended from 61.1 to 90 months. Among the high-grade gliomas, the improvement was more modest, with an increase from 64.9 to 75.2 months in World Health Organization grade III gliomas and from 11.3 to 14.5 months in grade IV gliomas. ${ }^{75-77,80-82,84,85}$

\section{CONCLUSIONS}

Intraoperative stimulation mapping is a reliable, robust method to maximize resection and minimize morbidity, even when removing gliomas within or near adjacent language pathways. Unlike motor function, speech and language are variably distributed and widely represented, thus emphasizing the use of language mapping in this particular patient population. Using modern language mapping techniques, in conjunction with standardized neuroanesthesia and neuromonitoring, the postoperative language resolution profile after glioma resection may be predictable. Specifically, in our experience, any additional language deficit incurred as a result of the surgery will improve by 3 months or not at all. Our experience also emphasizes the value of negative language mapping in the setting of a tailored cortical exposure. The value of extent of resection, however, remains less clear. Based on the available studies for both low-grade and highgrade hemispheric gliomas in the literature, there is growing evidence, however, that a more extensive surgical resection may be associated with a more favorable life expectancy for both low- and high-grade glioma patients. Because no class I evidence exists to support a particular management paradigm, the optimal combination of surgery, a chemotherapeutic agent, and radiation therapy remains unknown. Because it is unlikely that a prospective, randomized study will be designed to address these issues, retrospective, matched studies or prospective observational trials may be a more practical solution.

\section{REFERENCES}

1. Foerster O. The cerebral cortex of man. Lancet 1931;2:309-312.

2. Penfield W, Bolchey E. Somatic motor and sensory representation in the cerebral cortex of man as studied by electrical stimulation. Brain 1937;60:389-443.

3. Penfield W, Erickson TC. Epilepsy and cerebral localization. A study of the mechanism, treatment, and prevention of epileptic seizures. 1941.

4. Penfield W, Rasmussen T. Secondary sensory and motor representation. 1950.

5. Ranck JB, Jr. Which elements are excited in electrical stimulation of mammalian central nervous system: a review. Brain Res 1975; 98:417-440.

6. Haglund MM, Ojemann GA, Blasdel GG. Optical imaging of bipolar cortical stimulation. J Neurosurg 1993;78:785-793.

7. Haglund MM, Ojemann GA, Hochman DW. Optical imaging of epileptiform and functional activity in human cerebral cortex. Nature 1992;358:668-671.

8. Herholz K, Thiel A, Wienhard K, et al. Individual functional anatomy of verb generation. Neuroimage 1996;3:185-194.

9. Ojemann G, Ojemann J, Lettich E, Berger M. Cortical language localization in left, dominant hemisphere. An electrical stimulation mapping investigation in 117 patients. J Neurosurg 1989;71: 316-326.

10. Ojemann GA, Whitaker HA. Language localization and variability. Brain Lang 1978;6:239-260.

11. Ojemann GA. Individual variability in cortical localization of language. J Neurosurg 1979;50:164-169.

12. Ojemann JG, Miller JW, Silbergeld DL. Preserved function in brain invaded by tumor. Neurosurgery 1996;39:253-258.

13. Seitz RJ, Huang Y, Knorr U, et al. Large-scale plasticity of the human motor cortex. Neuroreport 1995;6:742-744.

14. Wunderlich G, Knorr U, Herzog H, et al. Precentral glioma location determines the displacement of cortical hand representation. Neurosurgery 1998;42:18-26.

15. Quinones-Hinojosa A, Ojemann SG, Sanai N, Dillon WP, Berger MS. Preoperative correlation of intraoperative cortical mapping with magnetic resonance imaging landmarks to predict localization of the Broca area. J Neurosurg 2003;99:311-318.

16. Seghier ML, Lazeyras F, Pegna AJ, et al. Variability of fMRI activation during a phonological and semantic language task in healthy subjects. Hum Brain Mapp 2004;23:140-155.

17. Tzourio-Mazoyer N, Josse G, Crivello F, Mazoyer B. Interindividual variability in the hemispheric organization for speech. Neuroimage 2004;21:422-435.

18. Turkeltaub PE, Eden GF, Jones KM, Zeffiro TA. Meta-analysis of the functional neuroanatomy of single-word reading: method and validation. Neuroimage 2002;16:765-780.

19. Tzourio N, Crivello F, Mellet E, Nkanga-Ngila B, Mazoyer B. Functional anatomy of dominance for speech comprehension in left handers vs right handers. Neuroimage 1998;8:1-16.

20. Dehaene S, Dupoux E, Mehler J, et al. Anatomical variability in the cortical representation of first and second language. Neuroreport 1997;8:3809-3815.

21. Steinmetz H, Seitz RJ. Functional anatomy of language processing: neuroimaging and the problem of individual variability. Neuropsychologia 1991;29:1149-1161.

22. Josse G, Herve PY, Crivello F, Mazoyer B, Tzourio-Mazoyer N. Hemispheric specialization for language: Brain volume matters. Brain Res 2006;1068:184-193.

23. Davies KG, Maxwell RE, Jennum P, et al. Language function following subdural grid-directed temporal lobectomy. Acta Neurol Scand 1994;90:201-206.

24. FitzGerald DB, Cosgrove GR, Ronner S, et al. Location of language in the cortex: a comparison between functional MR imaging and electrocortical stimulation. AJNR Am J Neuroradiol 1997;18:1529-1539.

25. Skirboll SS, Ojemann GA, Berger MS, Lettich E, Winn HR. Functional cortex and subcortical white matter located within gliomas. Neurosurgery 1996;38:678-684.

26. Ojemann GA. Models of the brain organization for higher inte- 
grative functions derived with electrical stimulation techniques. Hum Neurobiol 1982;1:243-249.

27. Ojemann GA. Cortical organization of language. J Neurosci 1991;11:2281-2287.

28. Ojemann GA, Creutzfeldt OD. Nervous System V, Part 2. 1987: 675-700.

29. Ojemann GA. Organization of language cortex derived from investigations during neurosurgery. Seminars in Neuroscience 1990;2:297-305.

30. Haglund MM, Berger MS, Shamseldin M, Lettich E, Ojemann GA. Cortical localization of temporal lobe language sites in patients with gliomas. Neurosurgery 1994;34:567-576.

31. Taylor MD, Bernstein M. Awake craniotomy with brain mapping as the routine surgical approach to treating patients with supratentorial intraaxial tumors: a prospective trial of 200 cases. J Neurosurg 1999;90:35-41.

32. Hochberg FH, Pruitt A. Assumptions in the radiotherapy of glioblastoma. Neurology 1980;30:907-911.

33. Wallner KE, Galicich JH, Krol G, Arbit E, Malkin MG. Patterns of failure following treatment for glioblastoma multiforme and anaplastic astrocytoma. Int J Radiat Oncol Biol Phys 1989;16: 1405-1409.

34. Ebeling U, Steinmetz H, Huang YX, Kahn T. Topography and identification of the inferior precentral sulcus in MR imaging. AJR Am J Roentgenol 1989;153:1051-1056.

35. Herholz K, Reulen HJ, von Stockhausen HM, et al. Preoperative activation and intraoperative stimulation of language-related areas in patients with glioma. Neurosurgery 1997;41:1253-1260.

36. Carpentier A, Pugh KR, Westerveld M, et al. Functional MRI of language processing: dependence on input modality and temporal lobe epilepsy. Epilepsia 2001;42:1241-1254.

37. Sartorius CJ, Berger MS. Rapid termination of intraoperative stimulation-evoked seizures with application of cold Ringer's lactate to the cortex. Technical note. J Neurosurg 1998;88:349351.

38. Duffau H, Capelle L, Denvil D, et al. Usefulness of intraoperative electrical subcortical mapping during surgery for low-grade gliomas located within eloquent brain regions: functional results in a consecutive series of 103 patients. J Neurosurg 2003;98:764778.

39. Duffau H, Capelle L, Sichez N, et al. Intraoperative mapping of the subcortical language pathways using direct stimulations. An anatomo-functional study. Brain 2002;125:199-214.

40. Lacroix M, Abi-Said D, Fourney DR, et al. A multivariate analysis of 416 patients with glioblastoma multiforme: prognosis, extent of resection, and survival. J Neurosurg 2001;95:190-198.

41. Sanai N, Berger MS. Mapping the horizon: techniques to optimize tumor resection before and during surgery. Clin Neurosurg 2008;55:14-19.

42. Sanai N, Mirzadeh Z, Berger MS. Functional outcome after language mapping for glioma resection. N Engl J Med 2008;358: $18-27$.

43. Berger MS. Lesions in functional ("eloquent") cortex and subcortical white matter. Clin Neurosurg 1993;41:443-463.

44. Chollet F, DiPiero V, Wise RJ, et al. The functional anatomy of motor recovery after stroke in humans: a study with positron emission tomography. Ann Neurol 1991;29:63-71.

45. Weder B, Seitz RJ. Deficient cerebral activation pattern in stroke recovery. Neuroreport 1994;5:457-460.

46. Lewine JD, Astur RS, Davis LE, et al. Cortical organization in adulthood is modified by neonatal infarct: a case study. Radiology 1994;190:93-96.

47. Maldjian J, Atlas SW, Howard RS, 2nd, et al. Functional magnetic resonance imaging of regional brain activity in patients with intracerebral arteriovenous malformations before surgical or endovascular therapy. J Neurosurg 1996;84:477-483.

48. Grady MS, Jane JA, Steward O. Synaptic reorganization within the human central nervous system following injury. J Neurosurg 1989;71:534-537.

49. Fandino J, Kollias SS, Wieser HG, Valavanis A, Yonekawa Y. Intraoperative validation of functional magnetic resonance imaging and cortical reorganization patterns in patients with brain tumors involving the primary motor cortex. J Neurosurg 1999;91:238-250.

50. Duffau H, Capelle L, Denvil D, et al. Functional recovery after surgical resection of low grade gliomas in eloquent brain: hypothesis of brain compensation. J Neurol Neurosurg Psychiatry 2003;74:901-907.

51. Thiel A, Herholz K, Koyuncu A, et al. Plasticity of language networks in patients with brain tumors: a positron emission tomography activation study. Ann Neurol 2001;50:620-629.

52. Duffau H, Bauchet L, Lehericy S, Capelle L. Functional compensation of the left dominant insula for language. Neuroreport 2001;12:2159-2163.

53. Black P. Management of malignant glioma: role of surgery in relation to multimodality therapy. J Neurovirol 1998;4:227-236.

54. Yasargil MG, Kadri PA, Yasargil DC. Microsurgery for malignant gliomas. J Neurooncol 2004;69:67-81.

55. Guthrie BL, Laws ER, Jr. Supratentorial low-grade gliomas. Neurosurg Clin N Am 1990;1:37-48.

56. Keles GE, Anderson B, Berger MS. The effect of extent of resection on time to tumor progression and survival in patients with glioblastoma multiforme of the cerebral hemisphere. Surg Neurol 1999;52:371-379.

57. Proescholdt MA, Macher C, Woertgen C, Brawanski A. Level of evidence in the literature concerning brain tumor resection. Clin Neurol Neurosurg 2005;107:95-98.

58. Sawaya R. Extent of resection in malignant gliomas: a critical summary. J Neurooncol 1999;42:303-305.

59. Grant R. Biopsy versus resection for malignant glioma (review). Cochrane Database Syst Rev 2006.

60. Nazzaro JM, Neuwelt EA. The role of surgery in the management of supratentorial intermediate and high-grade astrocytomas in adults. J Neurosurg 1990;73:331-344.

61. Pierga JY, Hoang-Xuan K, Feuvret L, et al. Treatment of malignant gliomas in the elderly. J Neurooncol 1999;43:187-193.

62. Hess KR. Extent of resection as a prognostic variable in the treatment of gliomas. J Neurooncol 1999;42:227-231.

63. Sanai N, Berger MS. Glioma extent of resection and its impact on patient outcome. Neurosurgery 2008;62:753-764.

64. Hegi ME, Diserens AC, Gorlia T, et al. MGMT gene silencing and benefit from temozolomide in glioblastoma. N Engl J Med 2005;352:997-1003.

65. Keles GE, Chang EF, Lamborn KR, et al. Volumetric extent of resection and residual contrast enhancement on initial surgery as predictors of outcome in adult patients with hemispheric anaplastic astrocytoma. J Neurosurg 2006;105:34-40.

66. Leighton C, Fisher B, Bauman G, et al. Supratentorial low-grade glioma in adults: an analysis of prognostic factors and timing of radiation. J Clin Oncol 1997;15:1294-1301.

67. Nakamura M, Konishi N, Tsunoda S, et al. Analysis of prognostic and survival factors related to treatment of low-grade astrocytomas in adults. Oncology 2000;58:108-116.

68. Philippon JH, Clemenceau SH, Fauchon FH, Foncin JF. Supratentorial low-grade astrocytomas in adults. Neurosurgery 1993; 32:554-559.

69. Rajan B, Pickuth D, Ashley S, et al. The management of histologically unverified presumed cerebral gliomas with radiotherapy. Int J Radiat Oncol Biol Phys 1994;28:405-413.

70. Shaw E, Arusell R, Scheithauer B, et al. Prospective randomized trial of low- versus high-dose radiation therapy in adults with supratentorial low-grade glioma: initial report of a North Central Cancer Treatment Group/Radiation Therapy Oncology Group/ Eastern Cooperative Oncology Group study. J Clin Oncol 2002; 20:2267-2276.

71. Yeh SA, Ho JT, Lui CC, et al. Treatment outcomes and prognostic factors in patients with supratentorial low-grade gliomas. Br J Radiol 2005;78:230-235.

72. Shaw EG, Daumas-Duport C, Scheithauer BW, et al. Radiation therapy in the management of low-grade supratentorial astrocytomas. J Neurosurg 1989;70:853-861.

73. Laws ER, Jr., Taylor WF, Clifton MB, Okazaki H. Neurosurgical management of low-grade astrocytoma of the cerebral hemispheres. J Neurosurg 1984;61:665-673. 
74. North CA, North RB, Epstein JA, Piantadosi S, Wharam MD. Low-grade cerebral astrocytomas. Survival and quality of life after radiation therapy. Cancer 1990;66:6-14.

75. Ito S, Chandler KL, Prados MD, et al. Proliferative potential and prognostic evaluation of low-grade astrocytomas. J Neurooncol 1994;19:1-9.

76. Nicolato A, Gerosa MA, Fina P, et al. Prognostic factors in low-grade supratentorial astrocytomas: a uni-multivariate statistical analysis in 76 surgically treated adult patients. Surg Neurol 1995;44:208-221.

77. Whitton AC, Bloom HJ. Low grade glioma of the cerebral hemispheres in adults: a retrospective analysis of 88 cases. Int J Radiat Oncol Biol Phys 1990;18:783-786.

78. Shibamoto Y, Kitakabu Y, Takahashi M, et al. Supratentorial low-grade astrocytoma. Correlation of computed tomography findings with effect of radiation therapy and prognostic variables. Cancer 1993;72:190-195.

79. Karim AB, Maat B, Hatlevoll R, et al. A randomized trial on dose-response in radiation therapy of low-grade cerebral glioma: European Organization for Research and Treatment of Cancer (EORTC) Study 22844. Int J Radiat Oncol Biol Phys 1996;36: 549-556.

80. Scerrati M, Roselli R, Iacoangeli M, Pompucci A, Rossi GF. Prognostic factors in low grade (WHO grade II) gliomas of the cerebral hemispheres: the role of surgery. J Neurol Neurosurg Psychiatry 1996;61:291-296.

81. Lote K, Egeland T, Hager B, et al. Survival, prognostic factors, and therapeutic efficacy in low-grade glioma: a retrospective study in 379 patients. J Clin Oncol 1997; 15:3129-3140.

82. Peraud A, Ansari H, Bise K, Reulen HJ. Clinical outcome of supratentorial astrocytoma WHO grade II. Acta Neurochir (Wien) 1998;140:1213-1222.

83. van Veelen ML, Avezaat CJ, Kros JM, van Putten W, Vecht C. Supratentorial low grade astrocytoma: prognostic factors, dedifferentiation, and the issue of early versus late surgery. J Neurol Neurosurg Psychiatry 1998;64:581-587.

84. Bauman G, Pahapill P, Macdonald D, et al. Low grade glioma: a measuring radiographic response to radiotherapy. Can J Neurol Sci 1999;26:18-22.

85. Johannesen TB, Langmark F, Lote K. Progress in long-term survival in adult patients with supratentorial low-grade gliomas: a populationbased study of 993 patients in whom tumors were diagnosed between 1970 and 1993. J Neurosurg 2003;99:854-862.

86. Claus EB, Horlacher A, Hsu L, et al. Survival rates in patients with low-grade glioma after intraoperative magnetic resonance image guidance. Cancer 2005;103:1227-1233.

87. McGirt MJ, Chaichana KL, Attenello FJ, et al. Extent of surgical resection is independently associated with survival in patients with hemispheric infiltrating low-grade gliomas. Neurosurgery 2008;63:700-707.

88. Smith JS, Chang EF, Lamborn KR, et al. Role of extent of resection in the long-term outcome of low-grade hemispheric gliomas. J Clin Oncol 2008;26:1338-1345.

89. Vecht CJ, Avezaat CJ, van Putten WL, Eijkenboom WM, Stefanko SZ. The influence of the extent of surgery on the neurological function and survival in malignant glioma. A retrospective analysis in 243 patients. J Neurol Neurosurg Psychiatry 1990;53: 466-471.

90. Shibamoto Y, Yamashita J, Takahashi M, et al. Supratentorial malignant glioma: an analysis of radiation therapy in 178 cases. Radiother Oncol 1990;18:9-17.

91. Curran WJ, Jr., Scott CB, Horton J, et al. Does extent of surgery influence outcome for astrocytoma with atypical or anaplastic foci (AAF)? A report from three Radiation Therapy Oncology Group (RTOG) trials. J Neurooncol 1992;12:219-227.

92. Simpson JR, Horton J, Scott C, et al. Influence of location and extent of surgical resection on survival of patients with glioblastoma multiforme: results of three consecutive Radiation Therapy Oncology Group (RTOG) clinical trials. Int J Radiat Oncol Biol Phys 1993;26:239-244.

93. Dinapoli RP, Brown LD, Arusell RM, et al. Phase III comparative evaluation of PCNU and carmustine combined with radiation therapy for high-grade glioma. J Clin Oncol 1993;11:1316-1321.

94. Jeremic B, Grujicic D, Antunovic V, et al. Influence of extent of surgery and tumor location on treatment outcome of patients with glioblastoma multiforme treated with combined modality approach. J Neurooncol 1994;21:177-185.

95. Nitta T, Sato K. Prognostic implications of the extent of surgical resection in patients with intracranial malignant gliomas. Cancer 1995;75:2727-2731.

96. Barker FG, 2nd, Prados MD, Chang SM, et al. Radiation response and survival time in patients with glioblastoma multiforme. J Neurosurg 1996;84:442-448.

97. Brown PD, Maurer MJ, Rummans TA, et al. A prospective study of quality of life in adults with newly diagnosed high-grade gliomas: the impact of the extent of resection on quality of life and survival. Neurosurgery 2005;57:495-504.

98. Buckner JC, Schomberg PJ, McGinnis WL, et al. A phase III study of radiation therapy plus carmustine with or without recombinant interferon-alpha in the treatment of patients with newly diagnosed high-grade glioma. 2001;92:420-433.

99. Lamborn KR, Chang SM, Prados MD. Prognostic factors for survival of patients with glioblastoma: recursive partitioning analysis. Neuro-oncol 2004;6:227-235.

100. Stark AM, Nabavi A, Mehdorn HM, Blomer U. Glioblastoma multiforme-report of 267 cases treated at a single institution. Surg Neurol 2005;63:162-169.

101. Ushio Y, Kochi M, Hamada J, Kai Y, Nakamura H. Effect of surgical removal on survival and quality of life in patients with supratentorial glioblastoma. Neurol Med Chir (Tokyo) 2005;45: 454-460.

102. Duncan GG, Goodman GB, Ludgate CM, Rheaume DE. The treatment of adult supratentorial high grade astrocytomas. J Neurooncol 1992;13:63-72.

103. Hollerhage HG, Zumkeller M, Becker M, Dietz H. Influence of type and extent of surgery on early results and survival time in glioblastoma multiforme. Acta Neurochir (Wien) 1991;113:31-37.

104. Huber A, Beran H, Becherer A, Prosenc N, Witzmann A. Supratentorial glioma: analysis of clinical and temporal parameters in 163 cases. Neurochirurgia (Stuttg) 1993;36:189-193.

105. Kowalczuk A, Macdonald RL, Amidei C, et al. Quantitative imaging study of extent of surgical resection and prognosis of malignant astrocytomas. Neurosurgery 1997;41:1028-1036.

106. Levin VA, Yung WK, Bruner J, et al. Phase II study of accelerated fractionation radiation therapy with carboplatin followed by PCV chemotherapy for the treatment of anaplastic gliomas. Int J Radiat Oncol Biol Phys 2002;53:58-66.

107. Phillips TL, Levin VA, Ahn DK, et al. Evaluation of bromodeoxyuridine in glioblastoma multiforme: a Northern California Cancer Center Phase II study. Int J Radiat Oncol Biol Phys 1991;21:709-714.

108. Pope WB, Sayre J, Perlina A, et al. MR imaging correlates of survival in patients with high-grade gliomas. AJNR Am J Neuroradiol 2005;26:2466-2474.

109. Prados MD, Gutin PH, Phillips TL, et al. Highly anaplastic astrocytoma: a review of 357 patients treated between 1977 and 1989. Int J Radiat Oncol Biol Phys 1992;23:3-8.

110. Puduvalli VK, Hashmi M, McAllister LD, et al. Anaplastic oligodendrogliomas: prognostic factors for tumor recurrence and survival. Oncology 2003;65:259-266.

111. Sandberg-Wollheim M, Malmstrom P, Stromblad LG, et al. A randomized study of chemotherapy with procarbazine, vincristine, and lomustine with and without radiation therapy for astrocytoma grades 3 and/or 4. Cancer 1991;68:22-29.

112. Tortosa A, Vinolas N, Villa S, et al. Prognostic implication of clinical, radiologic, and pathologic features in patients with anaplastic gliomas. Cancer 2003;97:1063-1071.

113. McGirt MJ, Chaichana KL, Gathinji M, et al. Independent association of extent of resection with survival in patients with malignant brain astrocytoma. J Neurosurg 2009;110:156-162.

114. Stummer W, Reulen HJ, Meinel T, et al. Extent of resection and survival in glioblastoma multiforme: identification of and adjustment for bias. Neurosurgery 2008;62:564-576. 